\title{
VI.
}

Aus einem Schreiben des Hrn Prof. Pleifchl,

Prag d. 30 Juli 182 I.

In den mir fo eben zugekonumenen 5ten Stücke Ihrer Annalen der Phyfik finde ich S. rog, dafs Hr. Dr. B rewft $r$ in Edinburg, der fich fo grofse und ausgezeichnete Verdienfie um die Naturwiffenfchaften erworben hat, behauptet, es lafle lich dem Glafe feine Spurödigkeit durch Auskochen in Waffer nicht benehmen, weil die mechanifche Befchaffenlieit des Glajes, es jey verkuhlt oder nicht verkishlt, durch die Hitze des kochendon Wafers nicht verändert werden könue, wie ihm feine Verfuche in polnrilirtem Lichte zeigten. Zwar kann ich dem Refultate diefer Seiner Verfuche in polarifirten Lichte, welche ich nicht wiederholt habe, nicht wider(prechen, aber mehrere mit ausgekochtem Glafe wirklich angefiellte Verfuche, bei welchen das Glas fehr fchnell wechfelnde und weit von einander entfernte Temperaluren oline zu fpringen annebmen mufste, kann ich als Gegenbeweis anfïhren. Sie linden fich im diefsjähr. Journal für Chemie Schweigg. u. Meinecke's H. 2

Atand für hlofs gelehrte Forfciung abgeben foll, nugefähr in dem Sinne desjenigen, was hier von Hrn Hanfteen angefübrt wird, (deffen fiderifch-magnetifche Ausfagen wir jedoch noch weit entfernt find, fïr ausgemachte Thatfachen anfehen zu dürfen); dafs mir aber aller Anthoil, den man dem grofsen, in den wiffenfchaftlichen Grundkenntuiffen unwiffenden Publikum an diefer Wioder-Erweckung einräumon follte, in fofern dadurch der Hang zum Wunderbaren, zur Myftik und zu blofsem Kitzel der Phantafie genährt werden wïrde. gefährich, ja für die Wiffenfchaft nachtheilig und lıerabwiirdigend dünken würde. Von Männern, die auf einige Aclitung Anfpruch machen, diefem unfeligen Hange in der Art gefröhnt zu fehen, wio das in fo vielen Gofichichtchen von thiexifchem Magnetismus, die fie in das Publikum fördern, gefchieht, (das ehrwiirdige Gewand der Wiffenfchaft erborgend um den Geift zu verweichlichen und herabzuwitr. digen, ftate ihn zu farken und zu erheben), ift fchmerz" lıaft für jeden, der es mit der Wahrheit treu meint, Gill. 


\section{[ 428 ]}

S. 268 . Wünfchenswerth dürfte es vielleicht feyn, um über den fraglichen Gegenftand ins Reine zu kommen, gleich dicke und gleich lange Glasfäbe von derlelben Glasmaffe anfertigen zu laffen, einige derfelben nuszukochen, andere nicht, und nun vergleichungsweife ihre Zähigkeıt durch Anhängen von Gewicht nach Mufchenbröck's und Sickingen's Methode zu unterfuchen. Hier, glaube ich, hätte man kein zweideutiges Refultat za befürchten, da der Durchmeffer der Glasfäbe durch ein dem Reilsen vorhergegangenes Ausdehnen derfelben nicht (wie bei den Metalldrähten) verändert worden wäre. Gelegentlich werde ich diefe Verfuche anftellen, um mir felbft vollkommene Leberzeugung zu verfchaffen.

VII. Zufatz zui Auffatz I S. 345 .

Am I Mai 1820 las Hr. La ug ier in der Akademie der Wirfenfchaften zu Paris einen Auffatz vor, überfchrieben: Thatfachcn zur chemifchen (icfchichte der Meteorfeine. Von den Beftandtheilen diefer fonderbaren Erzeugniffe hielt man drei für charakteriftifche, nämlich den Nickcl, das Clurom und den Schwcfel, letzteren am mindeften. Nickel aber glaubte man bisher charakterifire die Meteorffeine vorzüglich, da er fich in ihnen in bedoutenderer Menge und auch in dem Iogenannten meteorifchen Eifen findet, das man blos deshalb den Metoorfteinen anreihe. Hr. Laugier if aber der Meinung, dafs das Chrom der beftändigfte und die Meteorfoine am ficherften charakterifirende Beftandthell fey. Zu diefem Schlufs führte ihn die Zerlegung ziweier Meteorntine, die keinen Nickel und kein Clirom enthalten follten, eines von Stannern in Miliren vom 22 Mai 1808, und des zu Jonzee am I3 Iuni 1819 brrabgefallenen Steins. Im letztern findet fich in der That kein Nickel, wohl aber I Procent Clıom. Der erftere entiält dagegen nach Hrn Laugier's Analyfo Chrom und Nickel (?), aber nur $\frac{x}{2}$ Procent, wie der bei Verona'im J. 1063 berabgekommene Siein. Moch erklärt Hr. Laugier, warum die Gegenwart des Chroms den Clsemikern fo oft entgangen ift, und zeigt die Vorfichts-Regeln an, die uran beobachten mufs, um es gewifs'zu finden. 